\title{
TATA CARA DAN UPACARA SEPUTAR DAUR HIDUP MASYARAKAT JAWA DALAM SERAT TATACARA
}

\author{
oleh Venny Indria Ekowati
}

FBS Universitas Negeri Yogyakarta

\begin{abstract}
This article is about a research study conducted to describe the life-cycle manners and rituals according to a classical Javanese text titled Serat Tatacara (or $S T$, for short) written by Ki and Nyai Padmasusastra in 1863-1904. The text, which was the subject under study, was in prose and published by Kangjeng Gupremen in Batawi in 1907 in 2 volumes, the 1* of which containing 22 chapters covering 80 pages and the $2^{\infty}$ containing 18 chapters covering 105 pages. The content is presented in the form of dialogues or question-and-answer sessions between family members.

The research data were compiled by careful and direct reading on the subject. The instruments used for data compilation were data sheets. The data were analyzed by using a descriptive analysis technique practiced in such research.

The result of the research is a description of the life-cycle manners and rituals implied in $S T$, which, on the basis of the research result, are grouped into 3 phases: (1) the part covering the prenatal phase contains information about recognizing signs of pregnancy, what are forbidden and what are recommended during pregnancy, the ritual feast held when the pregnancy is 1 and 9 months old, and the manners practiced during childbirth, (2) the part covering the postnatal phase contains information about how to sever the placenta and what to do with it, how to take care of the mother and the baby after childbirth, and the postnatal rituals from brokohan, held right after childbirth, to slametan nyapih, held at the time the infant ceases being breastfed, and (3) the part covering childhood and adolescence contains information about the rituals of tetesan (the female counterpart of circumcision), pasah (the leveling of the horizontal edge of teeth), sukeran (banishment of bad luck), sunatan (circumcision), and tingalan (letting a girl be seen by visiting prospective parents-in-law) and the manners practiced by parents to find a spouse for their son or daughter.
\end{abstract}

Keywords: manners and rituals, life cycle, Serat Tatacara

\section{A. PENDAHULUAN}

Upacara daur hidup dalam komunitas masyarakat Jawa merupakan salah satu bentuk upacara adat yang masih lestari, sebagai wujud realisasi kompleks kelakuan berpola, kompleks ide, dan hasil karya manusia. Upacara tersebut dilakukan oleh orang Jawa dalam usahanya menjaga keseimbangan antara alam kodrati dan adikodrati. Sistem upacara daur hidup juga berangkat dari sistem religi masyarakat Jawa.
Seiring dengan perkembangan zaman yang semakin mengglobal, upacara daur hidup mengalami perkembangan dan perubahanperubahan baik dari sisi substansi maupun fungsi. Hal ini disebabkan adanya kecenderungan pola pikir yang semakin berorientasi praktis, perubahan pandangan, dan keyakinan, serta perkembangan ilmu pengetahuan dan teknologi. 
Upacara daur hidup pada masa sekarang ini cenderung mengalami penyederhanaan-penyederhanaan baik sarana maupun prosesinya. Kebanyakan masyarakat pada masa kini sudah tidak lagi mengetahui prosesi lengkap dan tata cara serta sarana yang utuh dalam penyelenggaraan suatu upacara. Oleh karena itu, untuk mengetahui sarana dan prosesi yang lengkap mengenai tata cara dan upacara seputar daur hidup, diperlukan sumber informasi yang mantap.

Naskah Jawa terutama yang sudah mengalami proses penggarapan secara filologis adalah naskah yang dapat digunakan sebagai sumber informasi mengenai tata cara dan upacara seputar daur hidup. Seperti yang diungkapkan oleh Baried (1994: 1) bahwa naskah atau karya-karya tulisan masa lampau merupakan peninggalan yang mampu menginformasikan buah pikiran, buah perasaan, dan informasi mengenai berbagai segi kehidupan yang pernah ada.

Salah satu naskah yang dapat dijadikan sumber informasi mantap untuk mengetahui prosesi, sarana, dan tata cara dalam upacara daur hidup adalah Serat Tatacara (selanjutnya disebut $S T$ ) yang dikarang oleh $\mathrm{Ki}$ Padmasusastra dan Nyai Padmasusastra pada tahun 1863-1904 M. ST dapat menjadi sumber penelitian yang mantap karena telah ditransliterasikan sesuai dengan kaidah filologis.

Sehubungan dengan itu, penelitian ini bertujuan untuk mendeskripsikan tata cara dan upacara daur hidup dalam salah satu teks Jawa klasik yang berjudul Serat Tatacara. Serat Tatacara yang menjadi subjek dalam kajian ini ditulis oleh Ki Padmasusastra dan Nyai Padmasusastra pada tahun 1863-1904 M.

Setiap kebudayaan yang dimiliki manusia pada hakekatnya terdiri dari unsurunsur kebudayaan universal. Seperti yang diungkapkan oleh Koentjaraningrat (1985: 203) bahwa:

Setiap kebudayaan yang dimiliki oleh manusia itu mempunyai tujuh unsurunsur kebudayaan yang bersifat universal, unsur kebudayaan tersebut antara lain: (1) bahasa, (2) sistem pengetahuan, (3) organisasi sosial, (4) sistem peralatan hidup dan teknologi, (5) sistem mata pencaharian hidup, (6) sistem religi, dan (7) kesenian.

A t a s d a s r pernyataa $n$ Koentjaraningrat tersebut, jelaslah bahwa suatu kebudayaan merupakan cerminan hidup dari suatu masyarakat sesuai dengan lingkungan tempat masyarakat tersebut tinggal.

Tujuh unsur kebudayaan universal tersebut kemudian membentuk suatu wujud kebudayaan. Koentjaraningrat (1987: 5) membedakan wujud kebudayaan menjadi tiga, yaitu:

(1) wujud kebudayaan sebagai suatu kompleks dari ide-ide, gagasan, nilainilai, norma-norma, peraturanperaturan dan sebagainya., (2) wujud kebudayaan sebagai suatu kompleks aktivitas kelakuan berpola dari manusia dalam masyarakat, (3) wujud kebudayaan sebagai benda-benda hasil karya manusia.

Atas dasar ketiga wujud kebudayaan tersebut disimpulkan bahwa kebudayaan memberi ciri nyata untuk mengangkat manusia dalam derajat yang tertinggi di antara makhluk Tuhan yang lain. Kebudayaan mengandung norma-norma, tatanan, dan nilai-nilai yang dimiliki dan dihayati oleh manusia dan masyarakat pemangku budaya tersebut.

Ketiga wujud budaya di atas, diaplikasikan dalam bentuk-bentuk upacaraupacara adat dan upacara tradisional. Salah satu komunitas masyarakat yang sangat kaya dengan upacara-upacara adat adalah komunitas masyarakat Jawa. Karena masyarakat Jawa sangat peka terhadap dimensi gaib dunia empiris yang diungkapkan dengan berbagai cara, misalnya dalam upacara-upacara rakyat yang mengusung mitos-mitos kuno tentang asal-usul suku, keselarasan dan gangguannya, perkawinan, kesuburan, dan penanaman padi (Suseno, 2001: 86-87).

Upacara daur hidup dalam komunitas masyarakat Jawa merupakan salah satu bentuk upacara adat yang masih lestari sampai dengan 
sekarang ini, sebagai wujud realisasi kompleks kelakuan berpola, kompleks ide, dan hasil karya manusia. Sistem upacara daur hidup berangkat dari sistem religi masyarakat Jawa yang dikenal sebagai Agami Jawi. Menurut Koentjaraningrat (1994: 324), sistem Agami Jawi mempercayai Tuhan Yang Maha Esa sebagai maha pencipta, dan penyebab kehidupan di dunia ini. Memandang Nabi Muhammad sebagai seseorang yang sangat dekat dengan Tuhan. Namun, di sisi lain, penganut Agami Jawi juga mempercayai tokoh-tokoh yang kemudian mereka anggap sebagai orang-orang keramat. Sistem Agami Jawi juga mempercayai adanya Dewa-Dewa, roh nenek moyang dan roh penjaga, roh, jin, setan, raksasa, dan mempercayai tentang akan datangnya ratu adil yang akan membawa keteraturan di muka bumi.

Konsep Agami Jawi yang lain adalah konsep mengenai kosmologi. Konsep inilah yang merupakan penyebab utama timbulnya berbagai ritual dan upacara-upacara adat, termasuk upacara daur hidup. Berbagai konsepsi mengenai kosmologi ini menurut Koentjaraningrat (1994: 329) dibagi menjadi tiga jenis mite, antara lain: (1) mite-mite dengan unsur-unsur dominan Hindu-Budha, (2) mitemite dengan unsur-unsur sinkretik Agami Jawi dan Islam, (3) mite-mite dengan unsur-unsur magis-mistik.

Sistem upacara daur hidup merupakan hasil pemahaman terhadap berbagai pemikiran yang kompleks dan heterogen. Resepsi dan pemahaman ini kemudian melahirkan bentukbentuk baru yang masih mencirikan pemahaman dan pandangan-pandangan masyarakat pemangkunya.

Upacara adalah rangkaian, tindakan atau perbuatan yang terikat kepada aturanaturan tertentu menurut adat atau agama; perbuatan atau perayaan yang dilakukan atau diadakan sehubungan dengan peristiwa penting (KBBI, 1995: 1108). Upacara daur hidup merupakan upacara yang diselenggarakan pada peristiwa-peristiwa penting sepanjang riwayat hidup seseorang (KBBI, 1995: 1108). Masyarakat Jawa memandang upacara daur hidup sebagai bagian dari kehidupan ritual yang menandai tingkatan usia dan kedewasaan seseorang. Upacara daur hidup dilaksanakan semenjak seseorang masih di dalam kandungan sampai akhir hayatnya.

Upacara daur hidup menurut Sedyawati (2006: 429-431), dibagi menjadi tiga tahapan penting dalam kehidupan manusia, yaitu (1) kelahiran, (2) perkawinan, dan (3) kematian. Upacara di seputar kelahiran yang sarat dengan makna simbolik antara lain mitoni, sepasaran, selapanan, selamatan weton pada setiap hari kelahiran. Pada awalnya, upacara tersebut mengandung arti magis, namun kemudian bergeser pada makna simbolisnya saja. Berkenaan dengan perkawinan, terdapat upacara panggih yang memuat berbagai macam prosesi sarat simbol. Sedangkan upacara seputar kematian antara lain trobosan, nenuwun di makam, tahlilan, mendhak, nyewu, ngijing, dan lain-lain.

Umumnya upacara daur hidup dibagi menjadi lima bagian menurut perjalanan hidup seseorang, yaitu: (1) adat- istidadat saat manusia dalam kandungan, (2) adat-istiadat saat manusia lahir, (3) adat-istiadat masa remaja yang meliputi sunatan atau tetesan, (4) adat istiadat perkawinan, dan (5) adat-istiadat kematian. Upacara daur hidup, menurut Koentjaraningrat (1987: 77-82) merupakan salah satu dari lima komponen religi. Setiap kompenen mempunyai peranannya sendirisendiri, tetapi tetap menjadi bagian dari suatu sistem yang berkaitan erat satu sama lain, seperti dalam bagan berikut. 


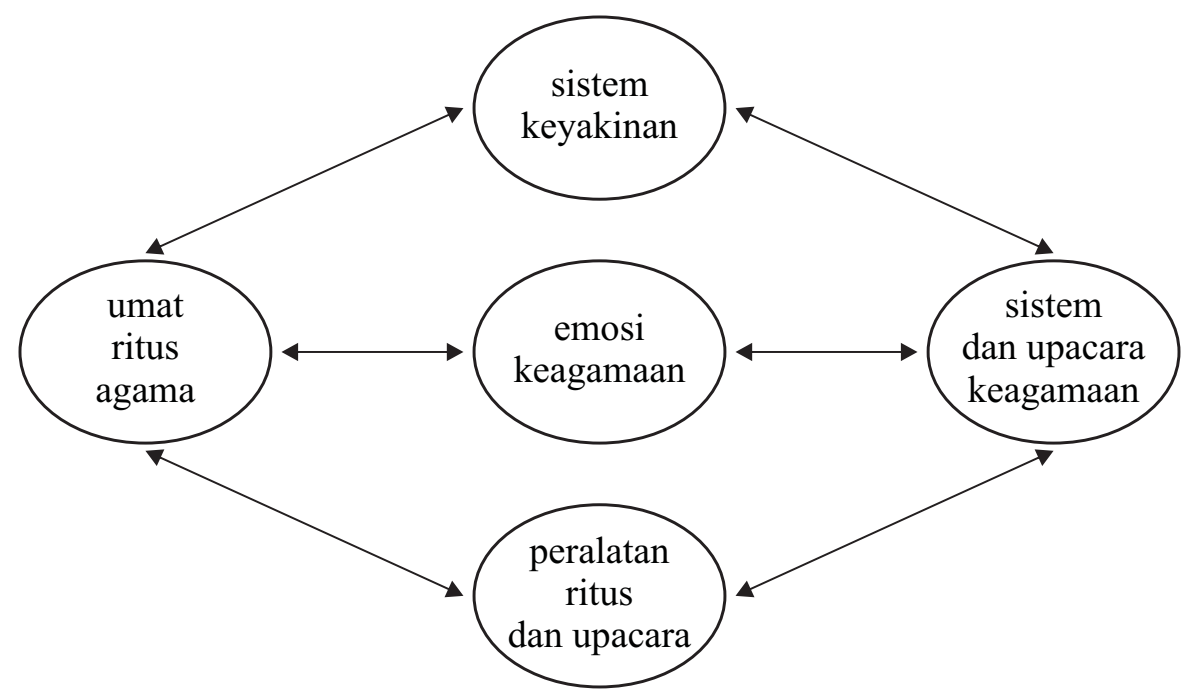

Upacara-upacara daur hidup sebagai salah satu wujud budaya, selalu mengalami perubahan-perubahan dan perkembanganperkembangan. Hal ini disebabkan adanya perubahan pola pikir dari masyarakat pemangku budaya. Perubahan pola pikir ini akan berpengaruh secara langsung terhadap sarana dan prosesi dalam upacara daur hidup. Murniatmo dalam Ririn (2000: 2) menyatakan bahwa:

Dewasa ini negara-negara berkembang termasuk Indonesia telah terjadi modernisasi, masuknya modernisasi ditandai dengan kemajuan ilmu dan teknologi dan tampak adanya mulai gejala mulai ditinggalkannya tata nilai yang telah lama berakar dalam alam pikir masyarakat pendukungnya.

Upacara daur hidup juga tidak lepas dari pengaruh globalisasi teknologi dan informasi. Walaupun dampak globalisasi informasi dan komunikasi sudah masuk dalam kehidupan masyarakat Jawa, ternyata masih ada sebagian masyarakat Jawa yang masih mempertahankan nilai-nilai tradisional. Hal tersebut terlihat dengan adanya pelaksanaan bernagai macam upacara, misalnya kematian, pendirian rumah, dan lain-lain, termasuk upacara panggih. Sebagian masyarakat tradisional ini, takut meninggalkan kebiasaan yang telah mengakar dalam segi-segi kehidupan mereka, dan masih setia mempertahankan tradisi peninggalan leluhurnya. Hal ini sesuai dengan pernyataan Suseno (2001: 1), yang mengemukakan bahwa kebudayaan Jawa memiliki ciri khas tersendiri. Ciri khas tersebut mempunyai kemampuan untuk membiarkan dirinya dibanjiri oleh kebudayaan asing, dan di dalam banjir tersebut, kebudayaan Jawa tetap mempertahankan keasliannya.

Namun arus globalisasi dan perubahan pola pikir membawa pergeseran dalam sistem tata cara dan upacara tradisi. Salah satunya adalah pergeseran makna penyelenggaraan upacara, dari kepercayaan yang bersifat magis menjadi sesuatu yang bersifat simbolis. Terkadang dilatarbelakangi pula dengan keinginan untuk mendapatkan ketenangan hidup. Namun seringkali penyelenggaraanya hanya dikarenakan tekanan sosial kemasyarakatan, dengan maksud mendapat pandangan positif dari masyarakat sekitar.

Pergeseran makna di atas, mendorong adanya perkembangan, perubahan sarana maupun prosesi dalam suatu upacara daur hidup. Salah satu contoh dalam hal pemakaian krobongan. Krobongan sudah jarang sekali digunakan pada upacara Tingkeban dan Sunatan. Proses siraman pada upacara Tingkeban pada masa sekarang ini hanya dilakukan di kamar mandi, tanpa membuat krobongan. Proses Upacara Sunatan juga sudah tidak dilakukan di dalam krobongan, melainkan 
hanya di dalam bilik atau kamar biasa. Selain itu, proses sunatan pada masa sekarang ini banyak yang dilakukan di rumah sakit oleh dokter spesialis.

Sarana penunjang yang berubah dalam upacara daur hidup, misalnya pada penggunaan besek dan sudhi. Pada masa sekarang ini besek sudah jarang dan diganti dengan kardus yang dirasa lebih praktis. Sudhi yang dulunya dibuat dari daun pisang, sekarang sudah dibuat dari kertas karton yang dilapisi dengan plastik.

Selain terdapat perkembanganperkembangan dan perubahan-perubahan dalam hal sarana, upacara daur hidup juga mengalami perkembangan dalam hal prosesi penyelenggaraan. Misalnya, dalam upacara sunatan terjadi pengurangan prosesi midodareni bagi anak yang akan ditetak. Selain itu anak, tidak perlu lagi berendam di dalam air pada pukul empat pagi, untuk melunakkan daging yang akan disunat. Materi upacara daur hidup juga mengalami perubahan-perubahan yang menuju ke arah kepraktisan dan penyederhanaan walaupun tidak mengurangi esensi yang ada.

Manusia adalah animal symbolicum, sebagai suatu ciri yang khas dan manusiawi. Simbol merupakan salah satu bagian dari aspek kebudayaan yang merupakan media dari adanya pemikiran manusia yang berasal dari adanya suatu kompleks ide-ide, gagasan, norma-norma, dan peraturan-peraturan. Secara lebih lanjut, simbol dapat diaplikasikan dalam setiap segi kehidupan manusia sebagai suatu kompleks aktifitas kelakuan berpola dari manusia dalam kehidupan bermasyarakat.

Secara etimologis, simbol berasal dari kata bahasa Yunani symbolos yang berarti 'tanda atau ciri'. Manusia dalam hidupnya selalu berkaitan dengan simbol yang berhubungan dengan kehidupan sehari-hari. Bahkan dalam proses interaksi, manusia juga menggunakan bahasa yang merupakan seperangkat sistem simbol. Bertolak dari pengertian di atas, maka dapat dikatakan bahwa manusia tidak bisa lepas dari simbol. Tingkah laku manusia selalu berdasarkan pada simbolsimbol. Herususanto (1987: 100) mengemukakan bahwa salah-satu tindakan manusia yang didasarkan pada simbol adalah tindakan-tindakan religius yang merupakan peninggalan zaman mitos. Diantaranya ialah pemberian sesaji bagi sing mbaureksa, mbahe, atau danyang yang berdiam di tempat-tempat yang dianggap angker atau wingit. Maksud diselenggarakannya sesaji ialah untuk mendukung kepercayaan mereka terhadap adanya makhluk halus seperti lelembut, dhemit, jin, dan yang mbaureksa. Mereka berdiam di tempat tersebar agar jangan mengganggu keselamatan dan ketentraman keluarga yang bersangkutan.

\section{B. METODE PENELITIAN}

Subjek penelitian ini adalah salah satu karya sastra Jawa yang berjudul ST. Serat ini digubah dalam bentuk prosa sebanyak dua jilid. Jilid pertama terdiri dari 22 bab, 80 halaman. Jilid kedua terdiri dari 18 bab, 105 halaman. Baik jilid pertama maupun kedua dijadikan sebagai subjek penelitian.

Penelitian ini menggunakan metode penelitian deskriptif yang digunakan untuk menemukan pengetahuan yang seluas-luasnya terhadap subjek penelitian yang berupa naskah Jawa (Ndraha dalam Widodo dan Muchtar, 2000: 15). Isi $S T$ dalam penelitian ini dideskripsikan secara apa adanya. Temuantemuan mengenai tata cara dan upacara seputar upacara daur hidup, disesuaikan dengan alur cerita yang terdapat dalam $S T$.

Teknik pengumpulan data yang digunakan untuk menjaring tata cara dan upacara daur hidup yang terdapat dalam $S T$ adalah metode observasi dan pencatatan. Secara garis besar, langkah-langkah metode deskriptif dalam pengumpulan data penelitian ini meliputi pembacaan secara cermat dan langsung terhadap subjek penelitian, terutama yang memuat hal-hal seputar tata cara dan upacara daur hidup. Pengumpulan data menggunakan instrumen penelitian yang berupa lembar data untuk mencatat data mengenai sarana dan prosesi, serta nilai-nilai simbolis upacara daur hidup yang terdapat dalam $S T$. 
Penelitian ini menggunakan teknik analisis deskriptif kualitatif yang berlaku dalam penelitian kepustakaan. Analisis deskriptif ini bertujuan untuk memberi gambaran mengenai upacara daur hidup yang terdapat dalam teksteks klasik Jawa. Rangkaian analisis data ini dibangun dalam tiga ranah, yaitu tesa, antitesa, dan sintesa. Widodo dan Muchtar (2000: 124), menyatakan bahwa langkah analisis data deskriptif dibangun seperti bangunan piramida terbalik seperti terlihat dalam gambar berikut.

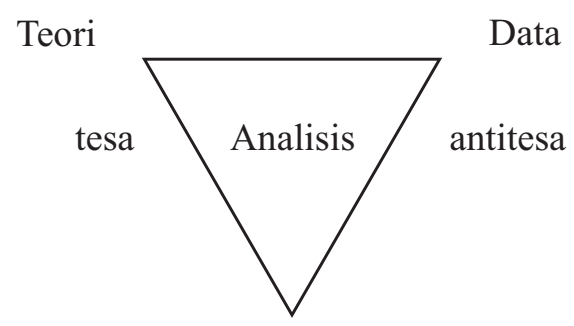

Analisis atau sintesa

Gambar di atas menunjukkan alur analisis deskriptif sebagai berikut: (1) posisi tesa diisi dengan teori-teori yang dipakai untuk merumuskan kerangka kerja penelitian. Kerangka kerja penelitian kemudian menghasilkan instrumen yang dipakai untuk menjaring data; (2) posisi antitesa diisi oleh data-data penelitian; (3) posisi sintesa merupakan analisis data yang telah dibangun pada posisi antitesa.

\section{HAS IL PENELIT IAN DAN PEMBAHASAN}

\section{Deskripsi Naskah}

ST dikarang oleh Ki Padmasusastra dan Nyai Padmasusastra pada tahun 1863-1904 M. Penggarapannya sampai dengan tahun 1904 dilakukan di nagari Batawi (sekarang Jakarta), kemudian penyelesaiannya dilakukan di Surakarta. ST yang dikaji dalam penelitian sudah merupakan naskah cetak yang diterbitkan oleh Kangjeng Gupremen di Batawi pada tahun 1907. Serat ini digubah dalam bentuk prosa sebanyak dua jilid. Jilid pertama terdiri dari 22 bab, 80 halaman. Jilid kedua terdiri dari 18 bab, 105 halaman. ST hasil cetakan Kangjeng Gupremen masih ditulis dengan aksara Jawa. Alih aksara kemudian dilakukan oleh Ny. Jumeri Siti Rumiyah, B. A., salah satu staf di Balai Kajian Sejarah dan Nilai Tradisi (Jarahnitra) Yogyakarta.

ST disajikan dalam bentuk dialog atau tanya jawab antaranggota keluarga. Keluarga yang menjadi pokok cerita dalam serat ini adalah keluarga seorang bangsawan yang bernama Tangkilan. Cerita berawal dari menantu Tangkilan yang sedang mengandung. Setelah itu, cerita bergulir melalui dialogdialog antara Tangkilan, istri, putra, menantu, pembantu-pembantu, tetangga, dan tokohtokoh lain dalam cerita. Dialog yang dilakukan secara keseluruhan memberikan keterangan mengenai tahapan-tahapan upacara daur hidup yang dilakukan oleh keluarga bangsawan tersebut.

Beberapa versi lain $S T$ dalam khasanah kesusastraan Jawa berdasarkan berikut studi katalog adalah sebagai berikut.

a. Tatacara Surakarta (kode UR.4), Serat Tatacara (kode LL.62 dan UR. 32) koleksi Fakultas Sastra Universitas Indonesia (Behrend dan Pudjiastuti, 1997: 1152).

b. Serat Tatacara kode 24245 koleksi Pura Mangkunegaran Surakarta (Girardet dan Soetanto, 1983:363). 


\section{Tatacara dan Upacara Prenatal}

Tabel 1: Hasil Penelitian Tatacara dan Upacara Prenatal dalam ST

\begin{tabular}{|c|c|c|}
\hline No. & Tata Cara/ Upacara & Sarana \\
\hline 1. & $\begin{array}{l}\text { Tata cara mengenali tanda -tanda } \\
\text { kehamilan, }\end{array}$ & - \\
\hline 2. & $\begin{array}{l}\text { Larangan-larangan selama masa } \\
\text { kehamilan }\end{array}$ & - \\
\hline 3. & $\begin{array}{l}\text { Anjuran-anjuran selama masa } \\
\text { kehamilan }\end{array}$ & Air garam, jamu-jamuan \\
\hline 4. & Wilujengan satu bulan & Jenang sungsum \\
\hline 5. & Wilujengan dua dan tiga bulan & $\begin{array}{l}\text { Sekul janganan, jenang, jajan pasar kembang } \\
\text { boreh }\end{array}$ \\
\hline 6. & Wilujengan empat bulan & Sega punar, ulam maesa setunggal, ketupat \\
\hline 7. & Wilujengan lima bulan & $\begin{array}{l}\text { Sekul janganan, jenang, jajan pasar kembang } \\
\text { boreh, uler-uler, enten-enten, rujak crobo }\end{array}$ \\
\hline 8. & Wilujengan enam dan tujuh bulan & Apem kocor, sekul janganan \\
\hline 9. & Wilujengan delapan bulan & Bulus angrem, singgatan \\
\hline 10. & Wilujengan sembilan bulan & Jenang ceprot, dhawet plencing \\
\hline 11. & Tingkeban & $\begin{array}{l}\text { Kembang setaman, wedhak, mangi } r \text {, sindu } \\
\text { atau cengkaruk, pon-empon, sriyatan, penyon, } \\
\text { sampora, pring sadhapur, tumpeng robyong, } \\
\text { sajen, ingon, }\end{array}$ \\
\hline 12. & $\begin{array}{l}\text { Tata Cara selama Proses } \\
\text { Kelahiran }\end{array}$ & Banyu emas, igaran \\
\hline
\end{tabular}

Tatacara yang dilakukan selama masa prenatal 'hamil sampai dengan melahirkan' tidak hanya melalui upacara-upacara tetapi juga dalam bentuk-bentuk pantangan-pantangan bagi wanita yang sedang hamil. Tatacara selama masa kehamilan dalam $S T$ disajikan melalui dialog antara Nyai Ajeng dan menantunya yang sedang hamil yaitu Raden Nganten. Deskripsi tatacara selama masa kehamilan disajikan dalam pembahasan di bawah ini.

\section{a. Tanda-Tanda Kehamilan}

Disebutkan dalam ST bahwa wanita yang sedang hamil memiliki ciri-ciri sebagai berikut: (1) payudara membesar dan membulat, (2) nafas pendek-pendek, (3) wajah sumunu mancur 'kehijau-hijauan', (4) merasa letih dan lesu, (5) mempunyai keinginan untuk menyantap jenis-jenis makanan yang rasanya pedas masam seperti rujak serta mempunyai keinginan berlebih terhadap jenis makanan tertentu. Tanda-tanda kehamilan tersebut dalam ST disebut dengan istilah nyidham 'ngidam'. Orang Jawa terkenal titen, hal-hal yang terjadi berulang-ulang kemudian dicatat untuk diturunkan sebagai ilmu kepada generasi berikutnya. Hal inilah yang kemudian menjadi kearifan lokal. Tanda-tanda kehamilan yang dikemukakan dalam $S T$ secara umum dikenal dengan istilah morning sickness. Tanda-tanda kehamilan secara ilmiah disebabkan karena faktor gula darah yang rendah, tekanan darah rendah, perubahan hormonal, kekurangan gizi terutama vitamin B6 dan zat besi, kelebihan konsumsi makanan olahan, pedas maupun berminyak (Balaskas, 2005: 86).

\section{b. Larangan-Larangan Selama Masa Kehamilan}

Selama masa kehamilan, terdapat beberapa larangan yang harus dipatuhi oleh wanita yang sedang hamil. Hal tersebut misalnya terdapat dalam acuan data berikut.

Sirikane: aja sok linggih tengah lawang, linggih lumpang utawa alu, mangan disangga, iku dadi pangane Bethara Kala ... ora kena mangan iwak kang angsare panas, kayata menjangan..., mangan duren lan maja iya ora kena...

Tata Upacara dan Upacara Seputar Daur Hidup Masyarakat Jawa ... (Venyy Indria Ekowati) 
'Pantangannya: jangan sekali-sekali duduk di tengah pintu, duduk di atas lumpang atau $a l u$, makan dengan piring tersangga tangan. (Jika dilaksanakan) akan menjadi mangsa Bethara Kala...tidak boleh makan daging yang menyebabkan panas, seperti daging kijang..., makan durian dan buah maja juga tidak boleh'

Larangan-larangan di atas pada dasarnya merupakan gugon tuhon. Gugon tuhon adalah perkataan atau dongeng yang dipercaya mempunyai daya atau kekuatan. Jika perkataan atau dongeng itu tidak dipatuhi, maka orang yang melanggarnya akan memperoleh kesialan dan kesengsaraan dalam hidupnya (Sutrisno, 1982: 44).Gugon Tuhon dibagi menjadi tiga, yaitu gugon tuhon satuhu, wasita sinandhi, dan pepali atau larangan. Gugon tuhon satuhu adalah kepercayaan bahwa seorang anak yang disebut dengan bocah sukreta akan menjadi mangsa Bethara Kala. Bocah sukreta misalnya bocah ontang-anting 'anak tunggal', bocah kedhana-kedhini 'sepasang anak laki-laki dan perempuan', dan lain-lain. Selain memangsa bocah sukreta, Bethara Kala juga akan memangsa orang-orang yang masuk golongan wong pangayam-ayam. Termasuk golongan wong pangayam-ayam antara lain orang yang memecahkan pipisan, merubuhkan dhandhang 'alat masak', dan lainlain. Bocah sukreta maupun wong pangayamayam akan terhindar dari Bethara Kala jika sudah melaksanakan upacara ruwatan. Gugon tuhon yang kedua adalah wasita sinandhi, yaitu nasihat yang tersamar yang pada umumnya diawal dengan kata ora ilok 'tidak pantas'. Gugon Tuhon yang ketiga adalah pepali atau wewaler, yaitu larangan-larangan turuntemurun dari par leluhur.

Termuat dalam $S T$ bahwa wanita hamil yang melanggar larangan yang tersebut di atas akan dimakan Bethara Kala, tentu saja hal ini tidak masuk akal. Menilik dari ciri dan fungsinya, larangan ini termasuk jenis gugon tuhon wasita sinandhi atau nasihat yang tersamar. Sebagai contoh kasus, larangan duduk di tengah pintu sebenarnya merupakan nasihat terselubung karena jika ada yang duduk di depan pintu, akan menghalagi orang yang lalu-lalang. Demikian juga makan dengan menyangga piring. Sebenarnya larangan tersebut bertujuan baik, karena makan dengan cara disangga sangat riskan sebab jika tidak waspada, piring yang sedang disangga dapat tumpah sewaktu-waktu. Menurut $S T$, wanita yang sedang hamil juga tidak diperbolehkan makan ikan sungsang. Karena jika makan ikan sungsang, dimungkinkan bayi yang dilahirkan juga akan sungsang.

Larangan memakan daging dan buahbuahan tertentu sebenarnya lebih bersifat medis. Daging kijang, buah durian, dan maja tidak boleh dimakan oleh wanita hamil karena makanan-makanan tersebut dapat meningkatkan suhu tubuh, membuat perut terasa panas, sehingga dikhawatirkan akan menimbulkan keguguran. Disebutkan pula dalam $S T$, adanya larangan memakai bungabungaan, hiasan sisir, memakai cincin dan gelang kecil karena mempunyai watak kandheg 'terhenti'. Bersumping bunga-bungaan, maka tangkai bunga tersebut akan terhenti di telinga, hiasan sisir terhenti rambut, cincin terhenti di pangkal jari, dan gelang kecil terhenti di pergelangan tangan. Larangan-larangan tersebut sebenarnya bersifat sugesti, dan merupakan harapan terselubung agar proses kehamilan dan kelahiran dapat lancar, tidak kandheg.

\section{c. Anjuran-Anjuran Selama Masa Kehamilan}

Selama masa kehamilan dianjurkan melakukan hal-hal sebagai berikut: (1) setiap hari Rabu dan Sabtu mandi dan mencuci rambut, memotong kuku, dan menghitamkan gigi, (2) sebelum tidur mencuci tangan dan kaki dengan air garam, dan (3) minum jamu-jamuan. Anjuran pertama selama masa kehamilan mempunyai makna kepasrahan. Kehamilan merupakan masa-masa riskan dan beresiko. Wanita yang sedang hamil dapat meninggal sewaktu-waktu. Mandi keramas dan memotong kuku merupakan salah satu cara untuk menjaga 
kebersihan. Jadi jika sudah membersihkan diri, setiap saat dipanggil Tuhan, sudah dalam keadaan bersih.

Anjuran kedua dimaksudkan untuk menjaga keselamatan ibu hamil. Karena mencuci tangan dan kaki dengan air garam dapat mencegah gigitan ular maupun binatangbinatang yang lain. Selain anjuran di atas, disebutkan pula dalam $S T$ bahwa wanita hamil harus minum jamu-jamuan untuk menjaga kesehatan.

\section{d. Wilujengan Selama Masa Kehamilan}

Wilujengan 'selamatan' selama masa kehamilan dilakukan dari bulan pertama sampai dengan bulan kesembilan. Wilujengan 'selamatan' selama masa kehamilan dilakukan dari bulan pertama sampai dengan bulan kesembilan. Wilujengan setiap bulannya diuraikan dalam keterangan berikut.

1) Wilujengan Satu Bulan

Wilujengan satu bulan kehamilan dinamakan ngebor-ebori. Sarana yang disiapkan adalah jenang sungsum 'bubur dari tepung beras yang dicampur dengan garam, dimakan dengan juruh santan'. Jenang sungsum mempunyai makna simbolik sebagai lambang kekuatan dengan harapan calon ibu diberi kekuatan untuk melalui masa kehamilan dan dapat melahirkan dengan lancar.

\section{2) Wilujengan Dua dan Tiga Bulan}

Wilujengan 2 dan 3 bulan kehamilan menggunakan sarana yang sama, yaitu:

- Sekul Janganan, berupa tumpeng yang dikelilingi dengan berbagai macam sayuran. Tetapi jenis sayuran sekeliling tumpeng berjumlah ganjil. Sekitar 5 sampai dengan 9 jenis. Sayur-sayuran ini kemudian dicampur dengan parutan kelapa yang dibumbui. Selain sayur-sayuran, untuk melengkapi tumpeng juga ditambahkan kedelai, gudhe 'kacang kara', ampas sayur kluwih yang sudah dicampur bumbu lada, sambal puyang, sambal laos, sambal kedelai, sambal wijen, sambal gepeng 'kacang putih', sambal kluwak, ampas wijen, dan ikan asin yang dibakar. Ditambah dengan satu butir telur yang dibelah menjadi lima. Semua sarana tadi dicampur di sekeliling tumpeng.

- Jenang 'bubur halus'. Berbagai macam jenang yang dipakai untuk wilujengan adalah jenang abrit (warnanya merah dan putih), jenang baro-baro yang dimasak dari tepung beras dan dibagi menjadi dua. Bagian pertama tepung beras dimasak dengan santan. Bagian kedua dimasak dengan gula jawa. Dipakai pula jenang katul, yang dibuat dari kulit padi halus yang kemudian dicampur dengan gula jawa disisir halus ditambah dengan parutan kelapa. Sedangkan jenang baro-baro dimaksudkan untuk milujengi saudarasaudara (kakang kawah adhi ari-ari) atau bagian-bagian dari rahim yang lahir bersama bayi.

- Jajan Pasar Kembang Boreh yang terdiri dari opak angin 'nama jenis makanan, yang jika dibakar akan bertambah besar', pisang pulut, pala kependhem (terdiri dari gembili dan kimpul), ampas kelapa yang diberi bermacam-macam warna, yaitu merah, hitam, kuning, biru, dan putih, carabikang 'srabi ukuran kecil' satu buah, kupat luwar 1 buah 'beras kuning yang dibungkus dengan janur seperti ketupat biasa, jika ditarik dapat lepas dengan mudah' (Poerwadarminta, 1939: 238a). Selain itu juga ditambahkan dengan empon-empon yang terdiri dari sunthi, kencur, kunir, lempuyang, jahe, bengle). Ditambahkan pula kapas, ampo 'tanah liat bakar', injet, dan nasi sayur yang dibungkus dengan daun.

\section{3) Wilujengan Empat Bulan}

Wilujengan empat bulan tidak memakai sarana yang terlalu banyak seperti pada kehamilan 2 dan 3 bulan. Sarana yang dipakai adalah sega punar 'yaitu sekul wuduk 'nasi uduk yang dicampur dengan kunyit dan sedikit asam'. Ditambah dengan lauk ulam maesa setunggal 'daging kerbau yang lengkap dengan jerowan dan satu biji mata', ditambah 
sambal goreng, dan ketupat empat buah.

\section{4) Wilujengan Lima Bulan}

Wilujengan lima bulan menggunakan sarana seperti pada wilujengan 2 dan 3 bulan, tetapi ditambah dengan uler-uler 'tepung beras dicampur air, pewarna, beras ketan yang juga diberi warna-warni, enten-enten 'parutan kelapa dicampur gula jawa', kemudian dibentuk bulat-bulat. Enten-enten dimakan bersama dengan beras ketan. Selain sarana di atas, para tetangga dekat dan keluarga juga diberi hantaran yang dimasukkan dalam ponthang 'semacam wadah yang terbuat dari janur kuning'. Agar antarikatan ponthang tidak lepas, diberi biting dari jarum lima warna (kuning emas, suwasa 'kuningan', salaka, tembaga, dan besi. Lambaran yang dipakai yaitu lemper siti 'cobek yang terbuat dari tanah'. Isi ponthang yaitu sekul punar, gorengan daging, dan makanan-makanan lain yang sudah disebutkan di atas. Ditambah dengan rujak crobo 'rujak yang dibumbui dengan sunthi kencur'.

\section{5) Wilujengan Enam dan Tujuh Bulan}

Wilujengan 6 dan 7 bulan dilakukan dalam satu waktu. Sarana yang dipakai yaitu apem kocor 'apem yang terbuat dari tepung beras dicampur dengan sedikit ragi, kemudian ditumbuk, dicampur dengan air, selanjutnya dijemur'. Sesudah jadi, kemudian dicetak, tanpa diberi bumbu. Karena diberi ragi, rasanya sedikit masam. Kemudian apem dimakan dengan juruh santan. Selain apem kocor, ditambah pula dengan sekul janganan.

\section{6) Wilujengan Delapan Bulan}

Sarana wilujengan delapan bulan yaitu bulus angrem "klepon yang ditutupi dengan srabi warna putih yang dihadapkan ke bawah'. Klepon melambangkan telur penyu, sedangkan srabi melambangkan kulit penyu.

\section{7) Wilujengan Sembilan Bulan}

Wilujengan sembilan bulan menggunakan jenang ceprot dengan harapan calon ibu mendapatkan kemudahan ketika melahirkan. Jenang ini dibuat dari tepung beras yang dicampur air dari santan kelapa dan gula Jawa, kemudian diaduk sampai kental. Setelah masak, kemudian dicampuri dengan pisang utuh yang sudah dikupas. Jenang ceprot kemudian dimasukkan dalam takir 'semacam wadah yang terbuat dari daun pisang'. Jika sudah memasuki akhir bulan ke-9, tetapi belum ada tanda-tanda akan melahirkan, diadakan wilujengan dengan sarana dhawet plencing. Dhawet ini dijual kepada anak-anak. Tetapi uang yang dibayarkan bukan uang sebenarnya, tetapi memakai wingka.

Wilujengan selama masa kehamilan pada dasarnya sama. Wilujengan yang penyelenggaraannya istimewa adalah wilujengan pada bulan ketujuh, yang disebut dengan upacara Tingkeban. Untuk mengadakan upacara ini biasanya dipilih hari Rabu atau Sabtu, sebelum bulan purnama. Tanggal yang dipilih harus ganjil. Boleh tanggal 3, 5, 7, 9, 11, 13 , atau 15 asalkan belum bulan purnama. Salah satu prosesi upacara adalah memandikan calon ibu. Biasanya mengambil waktu pada pukul 11.00 WIB siang. Prosesi upacara dimulai oleh calon nenek dari pihak suami yang menjatuhkan teropong. Jalannya teropong yang dengan cepat jatuh ke bawah, merupakan lambang permohonan agar proses kelahiran bayi juga dapat berlangsung dengan lancar dan cepat, seperti jalannya teropong.

Sesudah itu dijatuhkan pula melalui letrek, cengkir gadhing yang sudah digambari atau dilukisi tokoh Kamajaya dan Kamaratih, Panji dan Candra Kirana, atau Janaka dan Sembadra. Prosesi menjatuhkan cengkir gadhing ini agar kelak bayi yang lahir, jika lakilaki tampan seperti Kamajaya, Janaka, atau Panji, jika perempuan cantik seperti Kamaratih, Sembadra, atau Candra Kirana.

Sesudah dua prosesi ini berlangsung, calon ayah digandeng bapak dan mertua berangkat dari pendhapa menuju tempat dilangsungkannya prosesi. Sesudah itu, ibu si istri memecah atau membanting telur mentah, dan membelah cengkir gadhing yang tadi dijatuhkan. Prosesi ini melambangkan agar 
bayi yang dilahirkan sehat, tidak kurang suatu apa. Sesudah prosesi ini calon ibu menuju ke rumah. Jalan yang akan dilewati, diberi alas dengan kain mori. Mori melambangkan niat suci dan kepasrahan calon ibu kepada Tuhan YME. Sesudah itu, calon ibu berganti-ganti kain sebanyak tujuh kali.

Perlambang dalam prosesi ini terdapat dalam acuan data berikut:

...punika inggih ugi kalebet pasemon gampil anggenipun manak, kados saangenipun tapihan, plotra-plotro ...

'...itu merupakan perlambang, mudahnya proses kelahiran, seperti mudahnya kain-kain ini terlepas, plotra-plotro'
Kain-kain tersebut kemudian ditumpuk dan diduduki oleh calon ibu. Prosesi ini sebagai lambang agar proses kelahiran berlangsung dengan mudah, semudah terlepasnya tujuh buah kain tadi. Malamnya, diadakan pagelaran wayang dengan lakon Lairipun Gathotkaca "Lahirnya Gatotkaca'. Pringgawidagda (2003: 6-8), menyebutkan bahwa dalam proses Tingkeban, motif kain yang lazim dipakai yaitu Sidamukti, Truntum, Sidaluhur, Parangkusuma, Semenrama, Udan Riris, Cakar Ayam, Grompol, Lasem, dan Dringin. Secara umum, motif-motif kain ini mengandung harapan-harapan terhadap sifat dan nasib anak yang akan dilahirkan, seperti tampak dalam tabel berikut.

\begin{tabular}{|l|l|l|}
\hline No. & \multicolumn{1}{|c|}{ Motif Kain } & \multicolumn{1}{c|}{ Makna atau Harapan } \\
\hline 1. & Sidamukti & Menjadi orang yang sejahtera dan disegani banyak orang \\
\hline 2. & Truntum & Agar anak mewarisi kebaikan akal budi kedua orang tuanya \\
\hline 3. & Sidaluhur & $\begin{array}{l}\text { Anak yang akan lain menjadi pribadi yang santun dan berbudi } \\
\text { pekerti luhur }\end{array}$ \\
\hline 4. & Parangkusuma & $\begin{array}{l}\text { Harapan agar anak yang dilahirkan mempunyai akan setajam } \\
\text { parang (cerdas) }\end{array}$ \\
\hline 5. & Semenrama & $\begin{array}{l}\text { Agar anak yang akan dilahirkan mempunyai sifat halus, penuh } \\
\text { cinta kasih }\end{array}$ \\
\hline 6. & Udan riris & $\begin{array}{l}\text { Harapan agar anak menjadi pribadi yang mampu menyejukkan } \\
\text { dan memberi kesegaran }\end{array}$ \\
\hline 7. & Cakar Ayam & Anak pandai mencari rezeki seperti halnya ayam \\
\hline 8. & Grompol & $\begin{array}{l}\text { Agar anak mampu menyatukan seluruh keluarga, sehingga tidak } \\
\text { tercerai-berai atau } \text { nggrompol }\end{array}$ \\
\hline 9. & Lasem & $\begin{array}{l}\text { Kain bermotif garis vertikal, dipakai dengan harapan agar anak } \\
\text { senantiasa bertaqkwa kepada Tuhan YME. }\end{array}$ \\
\hline 10. & Dringin & $\begin{array}{l}\text { Kain bermotif garis horisontal, dipakai dengan harapan anak } \\
\text { mempunyai hubungan yang selaras dengan lingkungan sosialnya. }\end{array}$ \\
\hline
\end{tabular}

\section{e. Tata Cara selama Proses Kelahiran}

Disebutkan dalam ST, perempuan yang akan melahirkan diharuskan menghadap ke arah barat, sesuai dengan jalannya air. Ketika proses kelahiran akan dimulai, suami memangku si istri sambil meniup ubunubunnya. Pada saat memangku, rambut suami tidak boleh terikat (harus terurai), tidak boleh menggunakan hiasan sisir, memakai sabuk, kain tidak boleh ditalikan. Saat proses kelahiran, semua pintu rumah harus dalam keadaan tidak terkunci. Tali-tali ponjen 'kantong tempat jejamuan' juga harus terbuka, dan keris-keris harus dilepaskan dari wrangkanya. Tatacara ini pada dasarnya merupakan usaha untuk menghilangkan sifat kandheg 'terhenti'. Larangan-larangan tersebut sebagai simbol agar proses kelahiran berjalan lancar tidak ada yang ngendheg-ndhegi 'menghalang-halangi'. 


\section{Tatacara dan Upacara Pascanatal}

Tabel 2: Hasil Penelitian Tatacara dan Upacara Pascanatal dalam ST

\begin{tabular}{|c|c|c|}
\hline No. & Tata Cara/ Upacara & Sarana \\
\hline 1. & Cara memotong tali pusar & Welat, kendhil, kopohan \\
\hline 2. & $\begin{array}{l}\text { Cara merawat potongan } \\
\text { tali pusar }\end{array}$ & $\begin{array}{l}\text { Daun senthe, bathok bulu, kendhil, kemiri gepakjendhul, } \\
\text { kembang boreh, gereh pethek, dom, beras abang, lenga } \\
\text { wangi, lemper, tulisan berhuruf Arab dan Jawa, kain mori, } \\
\text { tindhih. }\end{array}$ \\
\hline 3. & $\begin{array}{l}\text { Cara merawat ibu dan } \\
\text { bayi sesudah proses } \\
\text { kelahiran }\end{array}$ & Madu dari bunga-bungaan, daging buah kelapa, sirih \\
\hline 4. & Brokohan & Sega asah, iwak kebo siji, pecel pitik, jangan menir \\
\hline 5. & Puput Puser & $\begin{array}{l}\text { Merica, bawang merah bakar, pisang ambon, gula kelapa, } \\
\text { nasi, sayur -sayuran, bubur merah, jenang baro-baro, jajan } \\
\text { pasar, benang lawe, daun-daunan, injet, jelaga, mainan } \\
\text { anak-anak, gandhik }\end{array}$ \\
\hline 6. & Sepasaran & Tumpeng, jenang merah putih, baro-baro, jajan pasar \\
\hline 7. & Selapanan & Tumpeng, inthuk-inthuk \\
\hline 8. & $\begin{array}{l}\text { Slametan } 40 \text { hari sesudah } \\
\text { melahirkan }\end{array}$ & Tumpeng, sayur mayur, banyu asem \\
\hline 9. & Tedhak siten & $\begin{array}{l}\text { Nasi dan sayur mayur, juadah tujuh warna, tebu, suji, air } \\
\text { sekar setaman, beras kuning, anggris, talen salaka, padi, } \\
\text { kapas, raja brana, kurungan ayam, }\end{array}$ \\
\hline 10. & Slametan satu tahun & Tumpeng dan sayur mayur, jenang gaul \\
\hline 11. & Slametan nyapih & $\begin{array}{l}\text { Ramuan kunyit, ketumbar, jamu -jamuan, larik, pupuk, } \\
\text { wedhak, dhukut sewu, wedang legon dhadhap }\end{array}$ \\
\hline
\end{tabular}

\section{a. Cara Memotong Tali Pusar}

Sesudah bayi lahir, dilakukan pemotongan tali pusar. Tali pusar dipotong dengan menggunakan welat 'bambu tipis dan tajam'. Welat dapat digunakan lebih dari satu kali, untuk adik-adik si bayi yang akan lahir kemudian. Oleh karena itu, ada istilah sedulur nunggal welat. Kain yang dipakai untuk melahirkan kemudian dicuci bersih dan dipakai sebagai kopohan. Artinya kain tersebut tidak akan dipakai lagi, hanya disimpan. Jika suatu saat bayi sakit, lazimya kain tersebut akan dipakaikan sebagai selimut.

\section{b. Cara Merawat Potongan Tali Pusar}

Potongan tali pusar yang sudah dicampur dengan kunyit, dimasukkan dalam kendhil yang sudah dialasi daun senthe bersama dengan kemiri gepak jendhul sebagai lambang suami istri, kembang boreh, gereh pethek, dom, beras abang, minyak wangi, garam, sirih, uang senilai satu gobang. Dimasukkan pula tulisan dalam huruf Arab dan huruf Jawa, dengan harapan agar kelak anak yang dilahirkan pintar mengaji dan membaca.

\section{c. Perawatan Ibu dan Bayi Sesudah Proses Kelahiran}

Sesudah bayi lahir dan dibersihkan, jika bayinya laki-laki dikumandangkan azan oleh kakek si bayi. Jika bayi perempuan dikumandangkan qomat. Setelah diazani atau diqomati, tempat tidur bayi digebrak sebanyak tiga kali, agar kelak bayi tidak menjadi orang yang mudah kaget. Sebelum bayi bisa menyusu kepada ibunya, menurut $S T$ terlebih dahulu diberi minum madu dari bunga-bungaan dan daging kelapa yang masih sangat lunak. Selain itu, terdapat pula larangan bahwa ibu yang baru saja melahirkan, tidak diperbolehkan tidur terus-menerus karena dikhawatirkan dapat meninggal tanpa sadar. 


\section{d. Upacara Brokohan}

Sesudah bayi lahir, diadakan slametan brokohan. Ketika bayi berumur 2, 3, 4 hari tidak ada slametan atau wilujengan khusus.

\section{e. Upacara Puput Puser}

Upacara yang istimewa selama pascanatal adalah upacara Puput Puser. Salah satu sarana yang penting dalam upacara ini adalah mainan anak-anak yang diperuntukkan bagi kerabat bayi (kakang kawah adhi ari-ari, sedulur papat lima pancer). Maksudnya kakang kawah karena kawah atau air ketuban pecah mendahului bayi, sehingga kawah dianggap sebagai saudara tua bayi, sedangkan ari-ari keluar sesudah bayi lahir, sehingga disebut adhi ari-ari. Sedulur papat lima pancer dimaksudkan bahwa saat bayi lahir di dunia, tidak hanya sendirian tetapi dengan empat saudara, yaitu kawah, ari-ari, darah, dan pusar, lima pancer maksudnya bayi itu sendiri sebagai pancer atau pusatnya. Konsep sedulur papat lima pancer ini dipakai sebagai salah satu konsep dasar kehidupan oleh masyarakat Jawa. Konsep ini sudah mendarah daging dalam jiwa setiap masyarakat Jawa. Hal ini terbukti dalam termuatnya konsep ini dalam primbon-primbon yang sampai sekarang ini masih kerap menjadi pedoman masyarakat Jawa dalam pengambilan keputusan seperti pindah rumah, menikahkan anaknya, memilih jodoh, dan lain-lain.

Salah satu primbon yang memuat mengenai konsep kakang kawah adhi ari-ari adalah Primbon Jawi. Disebutkan dalam Sura (2005: 27) bahwa saudara-saudara bayi tidak hanya 4, melainkan 8, yaitu (1) Celeng Demalung dari kawah, (2) Asu Ajag dari ari-ari, (3) Kalasrenggi dari darah, (4) Kutilapas dari bungkus, (5) Kalarandhing dari lendir, (6) Kalawekas dari kunir yang dijadikan sebagai alas, (7) Taliwangke dari usus ari-ari, dan (8) Tikus Jinanda dari bagian ari-ari yang terlepas.

\section{f. Upacara Sepasaran}

Bayi yang berumur sepasar atau lima hari juga dislameti, tetapi secara sederhana.

\section{g. Slametan Selapanan}

Saat bayi berumur 35 hari, diadakan upacara selapanan. Pada upacara ini, untuk pertama kali bayi dipotong rambutnya. Biasanya yang memotong adalah nenek si bayi. Hasil potongan rambut ini kemudian dijadikan satu dengan tai kalong dan pusar yang telah terlepas. Pusar yang telah terlepas ini jika dimakan oleh si bayi saat sudah besar, dipercaya dapat berfungsi sebagai jimat yang keampuhannya setara dengan ilmu kebal senjata.

\section{h. Slametan Empat Puluh Hari sesudah Melahirkan}

Empat puluh hari sesudah melahirkan, biasanya juga diadakan slametan. Jika memiliki biaya, maka slametan 40 hari sesudah melahirkan ini, diselenggarakan dengan meriah seperti pada saat tingkeban. Sarana slametan 40 hari adalah tumpeng dan sayur-mayur. Pada upacara ini diundang pula ibu-ibu untuk menyaksikan prosesi upacara. Prosesi upacara dilakukan dengan memandikan ibu yang baru saja melahirkan.

\section{i. Tedhak siten}

Tedhak siten menurut ST dilakukan saat bayi berumur 6 lapan atau pitung weton. Sarana pada slametan ini adalah beras kuning yang dicampur dengan uang anggris 'ringgit', wukon 'uang setengan rupiyah, talen salaka 'uang 25 sen yang terbuat dari logam berwarna putih', padi satu gengam, dan kapas satu dhompol. Jika kapas diambil oleh bayi pada saat upacara, dikatakan bahwa bayi dapat menjadi penguasa yang mampu membawahi beberapa wilayah. Jika yang diambil adalah uang ringgit (anggris), maka akan menjadi orang kaya. Sarana yang lain tidak diterangkan secara rinci dalam $S T$.

\section{j. Slametan Satu Tahun dan Slametan Nyapih}

Bayi yang berumur satu tahun, menurut $S T$ harus dibuatkan selamatan. Hitungan satu tahun, tidak mengacu pada netu, tetapi hanya berdasarkan hitungan tanggal dan tahun. 
Menurut ST, waktu yang paling baik untuk menyapih bayi, jika bayi laki-laki ketika berumur 15-16 bulan, jika perempuan 18-19 bulan. Jika melebihi umur tersebut baru disapih, menurut kepercayaan saat dewasa, anak tersebut akan menjadi orang yang bodoh.

\section{Tatacara dan Upacara pada Masa Anak- anak dan Remaja}

Tabel 4: Hasil Penelitian Tatacara dan Upacara pada Masa Anak-anak dan Remaja

\begin{tabular}{|l|l|l|}
\hline \multicolumn{1}{|c|}{ No. } & $\begin{array}{c}\text { Tata Cara/ } \\
\text { Upacara }\end{array}$ & \multicolumn{1}{c|}{ Sarana } \\
\hline 1. & Tetesan & $\begin{array}{l}\text { Plemek, daun -daunan, kain, sesajian (suruh ayu dan gedhang ayu, } \\
\text { gambir wutuhan, jambe tangan), uang suwang seperempat, kunyit }\end{array}$ \\
\hline 2. & Pasah & $\begin{array}{l}\text { Kain dodot ngrene, suruh ayu, gedhang ayu, kayu dhadhap srep, } \\
\text { wingkal, beras kencur, }\end{array}$ \\
\hline 3. & Sukeran & $\begin{array}{l}\text { Landha merang, air asam kawak, jeruk purut, pandan wangi, kembang } \\
\text { setaman, dupa }\end{array}$ \\
\hline 4. & Sunatan & Krobongan, lulur garutan, sujen, jampi kacekan \\
\hline 5. & Tingalan & Tumpeng, wedhus tujah, iwak kebo setunggal \\
\hline 6. & $\begin{array}{l}\text { Mencari } \\
\text { jodoh }\end{array}$ & Congkok \\
\hline
\end{tabular}

\section{a. Upacara Tetesan}

Upacara tetesan merupakan acara yang dilaksanakan pada saat anak perempuan beranjak remaja. Untuk rakyat jelata, upacara tetesan dilaksanakan pada saat si anak berumur 8 tahun, sedangkan untuk putri-putri dari keluarga bangsawan, upacara ini dilaksanakan saat anak berusia 10 tahun. Karena terdapat pandangan para keluarga bangsawan, bahwa menyelenggarakan upacara tetesan terlalu dini adalah hal yang memalukan.

\section{b. Upacara Pasah}

Upacara pasah 'meratakan gigi taring' dilaksanakan pada saat remaja. Untuk anak laki-laki dilakukan pada usia 18 tahun, untuk anak perempuan 12 tahun. Untuk anak perempuan, upacara pasah harus dilaksanakan sebelum si anak mendapat menstruasi yang pertama.

\section{c. Upacara Sukeran}

Upacara sukeran adalah upacara yang diselenggarakan saat anak perempuan pertama kali mendapat menstruasi. Upacara sukeran dilaksanakan pada saat menstruasi selesai. Selama tujuh hari dari menstruasi yang pertama, si anak tidak boleh menyisir rambut dan mandi, hanya boleh dilulur saja.

\section{d. Upacara Sunatan}

Upacara sunatan menurut $S T$ dilakukan saat anak laki-laki berusia 16 tahun. Sunat merupakan kewajiban bagi para pemeluk agama Islam. Namun ada perbedaan dalam segi umur anak yang akan disunat. Menurut hukum Islam, sunat bagi anak lelaki dilakukan saat bayi berumur 40 hari (Soebadyo, 2002: 115). Masyarakat Jawa menerima hal tersebut tetapi sekaligus melakukan adaptasi. Umur 40 oleh masyarakat Jawa dianggap terlalu dini, sehingga anak-anak dari masyarakat Jawa biasanya disunat pada umur 8-16 tahun.

Upacara Sunatan menurut ST dilaksanakan dengan berbagai persiapan. Salah satunya adalah persiapan tempat. Tempat yang digunakan untuk upacara sunatan biasanya dibangun di sebelah timur pendapa berupa krobongan dari bambu wulung yang dipasang pada 4 sisi. Prosesi upacara sunatan dimulai tiga hari sebelum hari H. Prosesi pertama adalah sengkeran atau pingitan. Selama dipingit, anak ditunggui secara bergantian oleh para sesepuh. Satu hari sebelum hari $\mathrm{H}$, diadakan lek-lekan 
'tidak tidur semalam suntuk' yang dimaksudkan untuk midodareni sunatan,

Saat hari $\mathrm{H}$, pukul 4 pagi si anak sudah mandi berendam di kamar mandi. Prosesi ini bertujuan agar daging yang akan disunat menjadi mengkeret, sehingga saat disunat darah yang keluar tidak terlalu banyak. Sesudah berendam dan mandi, si anak kemudian dirias. $\mathrm{Si}$ anak juga memakai kain sembagi merah untuk menampung darah yang keluar, agar tidak mengenai kain. Anak tidak diperkenankan memakai baju, badannya dilulur dengan boreh garutan 'lulur yang terbuat dari garut',

Pada pukul 06.00 pagi anak yang akan disunat kemudian diantar menghadap para tamu untuk meminta doa restu dengan cara pangabekti 'menyembah dan meminta doa restu' secara khusus kepada para tamu agung, anak kemudian diarak menuju krobongan tempat sunat diikuti para tamu. Tamu-tamu kemudian berdiri di depan krobongan untuk menyaksikan prosesi upacara. Sesudah selesai prosesi keseluruhan, para tamu disuguhi dengan hiburan tayuban sampai dengan sore hari. Malam harinya para tamu datang kembali ke rumah orang tua anak yang ditetak untuk menyaksikan pagelaran wayang kulit semalam suntuk.

\section{e. Upacara Tingalan}

Tingalan adalah upacara yang diadakan untuk memperingati kelahiran seseorang. Tingalan menurut $S T$ diperingati pada saat seseorang berulang tahun, dan penyelenggaraannya dilakukan pada saat weton orang yang bersangkutan. Sarana upacara tingalan adalah tumpeng dengan jumlah yang disesuaikan dengan umur orang yang berulang tahun. Dua buah tumpeng dibuat besar, melambangkan laki-laki dan perempuan, kemudian sisanya dibuat dengan ukuran lebih kecil. Selain itu juga harus disediakan wedhus tujah yaitu kambing yang dua buah kaki depannya berwarna putih. Kambing ini digunakan untuk menangkal pangapesing wuku 'kesialan wuku'. Tidak ada prosesi khusus dalam upacara tingalan. Para tamu hanya datang untuk mengucapkan selamat. Tamutamu yang datang merupakan mitra orang yang berulang tahun.

Keluarga Tangkilan yang menjadi inti cerita dalam $S T$ adalah keluarga bangsawan yang masih melestarikan tata upacara masyarakat Jawa. Namun konteks budaya dalam salah satu upacara yaitu Upacara Tingalan menunjukkan adanya pengaruh budaya Belanda. Hal ini terlihat pada prosesi upacara tingalan. Disebutkan dalam ST bahwa dalam acara ini yang hadir dikhususkan untuk tamu laki-laki. Acara diselenggarakan mulai pukul 20.00 WIB. Para tamu langsung dipersilahkan menikmati hidangan makan malam. Tengah-tengah acara diisi dengan toast cara Belanda. Cara ini diawali dengan pemukulan gelas oleh tuan rumah. Satu kali memukul gelas merupakan isyarat bagi para pelayan untuk mengisi gelas para tamu dengan minuman. Dilanjutkan dengan dua kali memukul gelas yang merupakan tanda bahwa seluruh gelas para tamu sudah terisi. Kemudian gelas kembali dipukul sebanyak 3 kali. Mendengar gelas dipukul $3 \mathrm{kali}$, para tamu serentak berdiri. Saat para tamu berdiri inilah, tuan rumah memaparkan doa-doa dan harapanharapan hidupnya. Sebelum mengucapkan harapan-harapannya tuan rumah memukul gelas terlebih dahulu sebanyak $3 \mathrm{x}$, kemudian $2 \mathrm{x}$, dan $1 \mathrm{x}$, baru berbicara. Sesudah prosesi toast dan makan malam, para tamu kemudian dipersilahkan untuk berpindah ke pendapa. Para tamu laki-laki menghabiskan malam di pendapa dengan bermain kartu, menikmati tari Gambyong, dan Tayuban.

Uraian di atas merupakan bukti bahwa persentuhan budaya antara bangsawan dan bangsa Belanda memang terjadi. Upacara di atas mengadaptasi tata cara ulang tahun bangsa Belanda, namun hiburan tetap khas Jawa yaitu Gambyong dan Tayuban. Selain susunan acara yang diadaptasi dari bangsa Belanda, hidanganhidangan pun dalam upacara tingalan juga mengadaptasi hidangan ala barat. Hal ini secara jelas termuat dalam buku Adat-Istiadat Jawa (Hardjowirogo, 1979: 101-104) bahwa 
hidangan yang tersedia dalam Upacara Tingalan biasanya merupakan campuran dari hidangan ala barat dan Jawa. Beberapa hidangan khas barat antara lain kaas-stangel, birthday cake, sosis, permen keras, buah kaleng, dan lain-lain. Namun hidangan khas Jawa juga tersaji dalam acara ini, seperti lapis legit, nasi opor, sambel goreng, timlo, nasi tumpeng, selada usar, dan lain-lain.

\section{f. Langkah-langkah Orang Tua Mencarikan Jodoh bagi Anaknya}

ST tidak membahas secara khusus mengenai upacara pernikahan. $S T$ hanya memuat cara-cara orang tua pada masa lalu untuk mencarikan jodoh bagi anaknya. Langkah-langkah mencarikan jodoh ini termuat dalam $S T$ halaman 75-80. Langkah-langkah tersebut sebagai berikut:

1) Orang tua yang akan mencarikan jodoh bagi anaknya akan memakai jasa seorang congkok 'mak comblang'. Congkok harus pandai berbicara, mampu mempromosikan kebaikan-kebaikan orang yang akan dijodohkan, budi baik orang tua calon, maupun kekayaan harta benda orang yang akan dijodohkan,

2) Congkok kemudian menjadi mediator penentu hari dan waktu untuk nontoni 'saling melihat calon'.

3) Bapak-ibu, anak laki-laki yang akan dijodohkan, beserta kerabatnya kemudian pergi ke rumah orang tua anak perempuan pada hari dan waktu yang telah ditentukan.

4) Sesudah beberapa waktu, bapak dari anak perempuan (tuan rumah) mempersilahkan bapak dari anak laki-laki untuk masuk rumah. Pada saat inilah anak perempuan yang ditontoni akan menyuguhkan pawohan 'buah-buahan' dan pakinangan 'peralatan dan sarana untuk mengunyah sirih' di depan para tamu.

5) Pada saat menyuguhkan buah-buahan dan pakinangan inilah, semua tamu termasuk anak laki-laki yang akan dijodohkan dapat melihat wajah calon istrinya. Jika pihak keluarga dan calon pengantin pria (cpp) setuju dan merasa cocok, ayah cpp kemudian mengirimkan surat lamaran. Jika keluarga dan cpp tidak berkenan dengan cpw, maka ayah cpp tidak perlu mengirimkan surat penolakan. Cukup dengan diam tanpa melakukan apa-apa. Jika tidak menerima kabar apapun cpw sudah jelas jika keluarga cpp tidak berkenan dengan calon pengantin wanita (cpw).

6) Surat dari ayah cpp diterima oleh cpw. Jika orang tua cpw juga setuju dengan cpp, maka surat lamaran tersebut akan dibalas dengan persetujuan, ditambahkan dengan hal-hal yang terkait dengan proses kelanjutan lamaran. Akan tetapi, jika ayah cpw tidak berkenan dengan cpp, maka surat lamaran tersebut dijawab dengan penolakan secara halus, dengan cara mengatakan bahwa cpw belum siap untuk menikah, belum mau berumah tangga, atau tidak baik menurut perhitungan waktu dan perjodohan.

7) Jika cpp merupakan anak dari keluarga bangsawan yang lebih rendah derajatnya, dan bermaksud menikahi cpw dari keluarga bangsawan yang lebih tinggi derajatnya, maka keluarga perempuanlah yang berhak nontoni cpp.

\section{PENUTUP}

\section{Kesimpulan}

Melalui penelitian ini dapat ditarik kesimpulan bahwa $S T$ memuat deskripsi tata cara dan daur hidup masyarakat Jawa yang terbagi dalam tiga fase, yaitu prenatal, pascanatal, serta masa anak-anak dan remaja. ST juga memuat simbol-simbol dari sarana dan prasarana upacara seputar daur hidup masyarakat Jawa. Mayoritas simbol-simbol yang digunakan merupakan lambang dari doa keselamatan dan permohonan kepada Tuhan Yang Maha Esa.

\section{Saran}

Penelitian ini hanya menggunakan sumber penelitian dari satu versi $S T$ saja. Oleh 
karena itu, diharapkan ada penelitian lain mengenai tata cara dan daur hidup masyarakat Jawa dengan menggunakan naskah-naskah sejenis yang ada di museum-museum dan perpustakaan-perpustakaan lain. Seperti naskah-naskah yang dikoleksi oleh Museum Sanabudaya, Tepas Kapujanggan Widya Budaya, dan Perpustakaan Nasional Republik Indonesia.

\section{DAFTAR PUSTAKA}

Balaskas, Janet. 2005. New Natural Pregnancy. Jakarta: Gramedia.

Baried, Siti Baroroh. 1994. Pengantar Teori Filologi. Jakarta: Pusat Pembinaan dan Pengembangan Bahasa Departemen Pendidikan dan Kebudayaan Jakarta.

Behrend dan Pudjiastuti, T.E. dan Titik. 1997. Katalog Induk Naskah-Naskah Nusantara Jilid 3-B: Fakultas Sastra UI. Jakarta: Yayasan Obor.

Girardet dan Soetanto. 1983. Descriptive Catalogue of the Javanese Manuscripts and Printed Books in the main Libraries of Surakarta and Yogyakarta. Wisbaden: Franz Steiner Verlag GMBH.

Hardjowirogo. 1980. Adat Istiadat Jawa (Sedari Seseorang Masih dalam Kandungan hingga Sesudah Ia Tiada Lagi. Bandung: Patma.

Herusatoto. 1987. Simbolisme dalam Budaya Jawa. Yogyakarta: PT. Hanindita Graha Widya.

Koentjaraningrat. 1994. Kebudayaan Jawa. Jakarta: Balai Pustaka. . 1985. Ritus Peralihan di Indonesia. Jakarta: Penerbitan Nasional Balai Pustaka.
1987. Kebudayaan Mentalitas dan Pembangunan. Jakarta: Gramedia. . 1987. Sejarah Teori Antropologi. Jakarta: UI Press.

Magnis Suseno. 2001. Etika Jawa. Jakarta: Gramedia.

Padmasusastra. 1907. Serat Tata Cara. Batawi: Kangjeng Gupremen.

Poerwadarminta, W. J. S. 1939. Baoesastra Djawa. Groningen Batavia: J. B. Wolters.

Pringgawidagda, Suwarna. 2003. Upacara Tingkeban. Yogyakarta: Adicita.

Pusat Pembinaan dan Pengembangan Bahasa. 1995. Kamus Besar Bahasa Indonesia. Jakarta: Balai Pustaka.

Sedyawati, Edi. Budaya Indonesia: Kajian Arkeologi, Seni, dan Sejarah. 2006. Jakarta: Raja Grafindo Persada.

Soebadyo, Haryati. 2002. Indonesian Heritage: Agama dan Upacara. Jakarta: Buku Antarbangsa.

Sulistyani, Ririn. 2000. Kajian Folklor Upacara Kupatan Jalasutra di Dusun Jalasutra Desa Sri Mulyo Kecamatan Piyungan Kabupaten Bantul Yogyakarta.Yogyakarta: Skripsi Jurusan PBD FBS UNY Yogyakarta.

Sura. 1995. Buku Primbon Jawi Lengkap Edisi Bahasa Indonesia. Solo: UD. Mayasari.

Sutrisno, As. 1982. Pathining Basa Jawa. Semarang: Mutiara Permata Widya.

Widodo, Erna dan Mukhtar. 2000. Konstruksi ke Arah Penelitian Deskriptif. Yogyakarta: Avyrouz. 